\title{
EN BUSCA DE EDÉN: \\ CONSIDERACIONES SOBRE LA OBRA DE ANA MARÍA MATUTE
}

\author{
Por \\ RUTH EL SAFFAR \\ University of Illinois at Chicago Circle
}

Edén representa un estado de conciencia en el cual se unen armónicamente los muchos términos en oposición que típicamente producen fricción y tensión. La edénica unión de opuestos ofrece no sólo el cese de la lucha que caracteriza nuestra estadía en la tierra, y de las pasiones que tal lucha provocan, sino bienestar material. Edén es paz y abundancia, y sus habitantes no distinguen entre lo bueno y lo malo: no poseen el concepto del bien y del mal.

Aquí quisiera mostrar, examinando algunas obras de Ana María Matute, y en particular La torre vigía, última obra suya publicada, cuán hondamente está grabada la imagen de Edén en su desgarrado universo imaginativo. Aunque muchos críticos han indicado la afinidad entre Matute y los escritores existencialistas, ${ }^{1}$ es fascinante observar, en casi todas sus obras, la persistente presencia del Jardín, o del "niño divino"." Este último, regularmente rechazado por los hijos de Caín, que también abundan en las obras de Matute, sigue sin embargo reapareciendo, en obra tras obra, tan inevitable como los que surgen para destruirlo.

Hay, entonces, un aspecto divino que se transparenta en el mundo, por otra parte tan cruel, de la ficción matuteana, aspecto que existe en relación dialéctica con el aspecto, mucho más sobresaliente, profano. Y es que la misma falta de esperanza de que adolecen tantos protagonistas suyos genera a

\footnotetext{
1 Ver, por ejemplo, los comentarios de Janet Winec off en "Style and Solitude in the Works of Ana María Matute", Hispania, 49(1966), 61-69; y más recientemente, su excelente libro sobre Matute, publicado bajo su nombre de esposa, Janet Díaz, Ana María Matute (New York: Twayne Publishers, Inc., 1971). Las caracterizaciones que Eugenio de Nora ofrece de la obra de Matute también subrayan su afinidad por una actitud existencialista frente a la vida. Ver Eugenio de Nora, La novela española contemporánea (Madrid: Gredos, 1962), II. Ver también Gemma Roberts, Temas existenciales en la novela española de postguerra (Madrid: Gredos, 1973).

2 Traduzco aquí el término "divine child" que usa C.G. Jung para señalar el arquetipo del niño como salvador.
} 
su vez la aparición de la enigmática figura divina. Digo enigmática porque esta figura está asociada claramente con lo inconsciente y no posee, por lo tanto, la facilidad de comunicación verbal que la integraría en la sociedad. La heroína de "La oveja negra", ${ }^{3}$ por ejemplo, sólo se siente feliz en el bosque. Le conforta pensar que puede perder sus posesiones allí donde serán reabsorbidas por la naturaleza. Es tal su afinidad con el mundo asocial, que su familia se desespera y piensa que la niña es no sólo enferma, sino también mala. Cuando, en la segunda parte de la obra, la heroína viaja imaginativamente por el mundo en busca de su muñeca Tomboctú, se encuentra, entre otras cosas, con un grupo de gitanos penitentes. Éstos la rechazan cuando ella insiste en que nunca ha pecado.

La asociación de Edén con lo inconsciente se desarrolla explícamente en "El rey de los zennos", de Algunos muchachos, publicado en 1968. En este cuento el niño divino, que se llama Ferbe, aprende debajo del mar que hay otro mundo mejor, del cual habla obsesivamente:

Ferbe... sólo repetía, tozudo: "cuando los hombres alcancen su forma verdadera y última, los zennos ascenderán desde algas y esponjas, en lo profundo del mar; y el mar y el cielo serán uno solo, y la verdad y la justicia reinarán; pero para ello es preciso que yo no muera..."4

A pesar de sus palabras-y a causa de ellas - es perseguido y muerto. Pero no termina allí el cuento. Ferbe sigue, bajo reencarnaciones distintas, apareciendo, siempre espontánea y misteriosamente, para ser, una y otra vez, destruido de nuevo por una sociedad hostil e incomprensiva.

Aunque muchas veces la figura que representa lo inconsciente aparece en las obras de Matute como un niño malcomprendido, en algunas obras toma esta figura la forma de duende o de gnomo, como en "La razón", publicado en 1961 en la coleccion Tres y un sueño. ${ }^{5}$ Otras veces la figura divina toma forma de animal. En "El perro perdido", de Historias de la Artámila 6 , un niño enfermo ve un perro viejo y hambriento. Los hermanos del niño creen que el perro está poseído por un espíritu malvado, y tratan de matarlo. El niño enfermo protesta tanto que los hermanos dejan vivir al perro. Esa misma noche el perro, que se ha quedado en la calle frente a la casa donde está el niño, asume la enfermedad de éste, muriendo y dejando sano y salvo al niño.

\footnotetext{
${ }^{3}$ La heroína, que es también la narradora del cuento, no tiene nombre. El cuento aparece en una colección de cuentos llamado Tres y un sueño (Barcelona: Ediciones Destino, 1961).

${ }^{4}$ Algunos muchachos (Barcelona: Ediciones Destino, 1968), pp. 117-118.

${ }^{5}$ Barcelona: Ediciones Destino, 1961.

${ }^{6}$ Barcelona: Ediciones Destino, 1961.
} 
La atención que prestan ciertos protagonistas de Matute a los pobres, enfermos, malcomprendidos y rechazados recuerda las palabras de Jesus: "en cuanto lo hicisteis a uno de estos mis hermanos más pequeños, a mí lo hicisteis"(Mateo 25:40). Desde el punto de vista de la conciencia, cercada por la envidia y la codicia, y basada en la división y el cálculo, lo inconsciente puede parecer una cosa deformada y de poco valor. $Y$ sin embargo, como amenaza Tano, el gnomo de "La razón":

Escrito está, que el día en que ni un solo mortal crea en nosotros, dejaremos todos de existir... Y los elfos que se esconden en los pétalos, en el interior de los juncos, en las vainas de las plantas, se convertirán en negra simiente que nunca dará fruto... Los pequeños geniecillos del fuego, se pegarán en el interior de las chimeneas...y los esparcerá el deshollinador al viento, y sólo serán eso: humo, que ahuyentará a los niños y a los pájaros. ${ }^{7}$

Ignorar las fuerzas y elementos de la naturaleza significa su destrucción.

En la ficción creada por Matute hay una muy marcada división entre la conciencia y la inconsciencia. La lucha por reunirlas-por reestablecer Edén-forma la base de su obra. En el nivel social la división se ve en la recurrente, casi obsesiva, presentación de niños de padres divorciados. Matia, por ejemplo, en Primera memoria, novela publicada en 1960, entra en el mundo novelístico como víctima de una serie de expulsiones de "Edén". Sus padres se habían divorciado, luego murió su madre, le quitan a la niña el a ma que la cuidaba, y la niña por fin es expulsada de su escuela católica, "Nuestra Señora de los Ángeles". La serie representa, seguramente, una "overdetermination' 8 de la imagen de la Caída. Y, significativamente, es en una breve recuperación del Jardín-en un momento de paz cuando Matia, en un verdadero jardín, comparte con Manuel sus sentimientos más íntimoscuando se hace transparente el estado de división a que ha sido expuesta.

La división entre los sexos que se manifiesta en divorcio en tantas obras de Matute llega al protagonista como herencia no sólo de los padres, sino de los abuelos. Proliferan en la obra de Matute abuelos que se dedican al alcohol y a la pornografía, y abuelas que se encierran cada vez más en una moralidad rígida que acompaña un rechazo total de sus disolutos esposos. Matia, que reaparece como adulto en La trampa, la última novela de la trilogía iniciada con Primera memoria, rechaza ya a su vez un esposo alcohólico, y deja que la convenzan de abandonar a su niño de dos años. La enfermedad de división se trasmite de generación a generación.

7 Tres y un sueño, pp. 17-18.

${ }^{8}$ Uso aquí, sin traducir, el término que usó Freud para indicar cómo, en sueños, se multiplican las maneras de representar una sola idea. 
Y sin embargo, la presencia del niño abandonado, que señala la agonizante división entre los sexos, la división en el mundo, representa no sólo la perpetuación de tal situación para la nueva generación-más envidia, más codicia, más odio - sino también la posibilidad, siempre latente, de recuperar la unión perdida. Señala reunión, aunque breve, y la promesa de un mundo nuevo, como tantas veces profetizaba Ferbe.

Este mecanismo de pérdida y de recuperación encadena las generaciones en una repetición sin fin de la lucha entre Caín y Abel, figuras tan obsesivas en las obras de Matute como es la de Edén. ${ }^{9}$ Matia se pregunta, en Primera memoria, "¿Será verdad que la vida arranca de escenas como aquélla? ¿Será verdad que de niños vivimos la vida entera, de un sorbo, para repetirnos después, estupídamente, ciegamente, sin sentido alguno?"10 Matute ha dicho, hablando de sus propias novelas, algo semejante-que cada autor reescribe la misma obra, elaborando siempre algunos temas favoritos." Hay, entonces, una relación entre la búsqueda frustrante asumida por sus protagonistas para reencontrarse en Edén, y el esfuerzo de Matute de romper con las obsesiones que limitan a la vez que generan su obra.

En la última obra publicada de Matute, La torre vigía, de 1971, se ve un comienzo-pero sólo un comienzo-del proceso de romper la barrera que mantiene firmemente separados el mundo de lo inconsciente y el mundo

\footnotetext{
${ }^{9}$ Muchos críticos han comentado la presencia de Caín y Abel en la obra de Matute. Ver por ejemplo, Janet Winecoff Díaz, "The Autobiographical Element in the Works of Ana María Matute". Kentucky Romance Quarterly, 15 (1968), 144-145; Margaret Jones, "Religious Motifs and Biblical Allusions in the Works of Ana María Matute", Hispania, 51 (1968), 416-423; George Wythe, "The World of Ana Maria Matute", Books Abroad, 40 (1966), 24-25; and Eugenio de Nora, La novela española contemporánea, p. 292. Pocos, sin embargo, citan a Edén como preocupación de Matute. Una excepción es Santos Sanz Villanueva, en Tendencias de la novela española actual (1950-1970) (Madrid: Cuadernos para el Diálogo, 1972). Hablando de motivos constantes en la obra de Matute, cita "el mundo de los niños y de los jóvenes y el tema con él relacionado del cainismo; el de la incomunicación humana; el de la búsqueda del paraíso imposible..." (p. 179).

${ }^{10}$ Este pasaje de Primera memoria (Barcelona: Ediciones Destino, 1960), p. 20, también es citado por Margaret Jones en "Temporal Patterns in the Works of Ana María Matute", Romance Notes, 12(1971), 1-7, donde ella hace notar la persistencia de patrones básicos e inca mbiables que se encuentran en la obra de Matute.

"Gonzalo Sobejano, en un lúcido estudio de La torre vigía nota que con este libro Matute "ha intentad o... dar expresión a un permanente a nhelo suyo: la superación del odio en cua lquiera de sus formas (calumnia, envidia, venganza, sadismo, guerra)", en Novela española de nuestro tiempo (Madrid: Editorial Prensa Española, 1975), p. 478. Pero queda por decidir si el héroe realmente, como él constata, traspasa los opuestos. Dice Sobejano: "Con esta constante oposición de extremos se prepara la fuga trascendente del héroe, que no es decisión hacia uno de los extremos, sino ascensión hacia esa especie de estación total o vértice cósmico..." (p. 478).
} 
social. Con La torre Matute cambia radicalmente el ambiente, pero no los conflictos sociales que predominaban en sus obras anteriores. En lugar de la España contemporánea, los protagonistas de su nueva y última novela habitan unas estepas frías y secas en la Europa de siglo X. Sigue habiendo, sin embargo, una interacción básica entre la gente de la tierra, brutalizada por su pobreza e ignorancia, y una aristocracia en plena decadencia. Y símbolos como sol y viento, que siempre tuvieron en la obra de Matute una fuerza especial, toman un lugar casi central en La torre. Sin las distracciones que ofrece un contex to moderno, sol y viento, con el deseo sexual, el homicidio, la violencia, la envidia, y la traición, aparecen como fuerzas elementales, determinantes en las vidas de los protagonistas.

Pero la omnipresencia del mal, como hemos visto, trae consigo, tan inesperada como inevitablemente, la intuición de una fuerza del bien, más poderoso aún. Y es dentro de la conciencia del narrador/héroe de La torre donde Matute presenta los comienzos de la lucha a pocalíptica entre las fuerzas de la luz y las de las tinieblas lo que aquél llama "el Gran Combate". El impacto del libro se debe no a sus muchas escenas de violencia sino al conflicto elemental de opuestos que el protagonista, sin éxito, trata de asimilar.

Digo "sin éxito" con un sentid o de pesar mezclado con uno de complacencia. Pesar, porque La torre representa el esfuerzo más ambicioso de Matute hasta la fecha de sobrepasar los conflictos angustiantes que marcan toda su obra anterior. Pero siento complacencia porque son precisamente esos conflictos los que han provocado sus tan ricas y llamativas obras. En La torre se siente ya la lucha centrada en la autora, entre el ser, que quisiera ser íntegra, y el escritor, que depende del conflicto. La victoria del ser, aparentemente, negaría la existencia-la necesidad de existir-del escritor.

Quizás... quizás estos casi diez años sin publicar advierten la victoria del ser, o peor, la inmersión de la conciencia dentro de lo inconsciente. En todo caso, sentimos que con La torre la autora se encuentra en una encrucijada. Tiene que haber una relación entre la lucha tan claramente entablada en la obra y el raro silencio posterior de su autora, tan prolífica en las décadas anteriores.

El narrador/héroe de $L a$ torre, raras veces al principio, pero más persistentemente al fin, recibe visiones de paz y de reconciliación. Pero no es capaz de mantener firme las verdades que le llegan. Sus convicciones sobre la existencia de un mundo mejor se esfuman frente a la incesante crueldad y violencia que forma su experiencia diaria. Al fin de la novela, vemos con más y más frecuencia oscilar el protagonista entre creer en su torre de visiones o en la vida de envidia y maldad que lo circunda. Cerca del final el héroe, luchando contra el miedo de sus tres hermanos enemigos dice: 
"No hay miedo, no hay muerte...," me repetía. Pero bien sabía que únicamente en lo más alto de la torre vigía lograba poseerme tal convencimiento. ${ }^{12}$

Sólo en la torre-en los más altos grados de la conciencia-logra liberarse del choque de opuestos que tanto le angustia. Todo esfuerzo por mantener esa cima de comprensión le resulta vano. El vigía de la torre, por quien recibe sus visiones, le dice:

No intentes, joven caballero, desviar el cauce de tu vida, por brillante que imagines este esfuerzo... Baja de nuevo al mundo de los guerreros, de la víctima y de los verdugos; vuelve junto a tu señor, que tanto te ama; y recuerda que no han visto tus ojos el Gran Combate. ${ }^{13}$

El protagonista central y narrador en primera persona de La torre vigía es un compuesto de los muchos niños divinos que pueblan las obras de Matute. El héroe aprende muy pronto en el camino de su vida que los hombres tienden ritualmente a disponer de las personas más débiles de su sociedad, cargándolas primero con la culpa por todas las maldades que sufre la colectividad. Despierta, metafóricamente, a un mundo extasiado por el sacrificio ritual de la maldad. Como muchos otros niños matuteanos, nace el héroe de La torre de una familia relativamente privilegiada. Pero como los otros-como Juan de "Algunos muchachos", como Matia y Borja de Primera memoria, como Perico de "La isla" 14 - es emocionalmente abandonado por padres distraídos y preocupados por problemas propios.

El héroe de La torre también sigue el patrón familiar de muchos protagonistas anteriores en la obra de Matute en su rechazo rotundo del mundo de los adultos. Como explica muy bien Margaret Jones en su The Literary World of Ana Maria Matute, el mundo del niño es radicalmente divorciado del mundo de los adultos, y los más de los niños, o mueren, o pierden por completo su inocencia y capacidad de fantasía al despedirse de la niñez. ${ }^{15}$ El héroe de La torre renuncia el mundo de los adultos precisamente en el día en que había sido investido como caballero en él. Tras una noche de vigilia y de duda, decide por fin dejarse matar por sus hermanos envidiosos en vez de ocupar el lugar privilegiado que el barón-jefe de su mundo--le había predestinado.

Pero, a pesar de las semejanzas entre este protagonista y otros niños abandonados y crucificados de la obra anterior, hay indicios en esta novela,

12 La torre vigia (Barcelona: Editorial Lumen, 1971), p. 213.

${ }^{13}$ La torre vigia, p. 210.

14 "La isla" aparece como el segund o cuento de la colección Tres y un sueño.

15 The Literary World of Ana Maria Matute (Lexington: The University Press of Kentucky, 1970). Ver especialmente su capitulo 2, "The World of Childhood-Una edad total y cerrada". 
por primera vez, de progreso. Un cambio significativo es que el niño divino de La torre ha asumido el papel de narrador. Pero más importante, ya que en varios otros cuentos una voz de la inconsciencia ha proveído el punto de vista para la novela, el niño divino aquí tiene acceso al mundo social. Es poderoso. Tiene control sobre sí mismo y ha atraído la atención y estimación de los más altos de la sociedad---del barón y de la baronesa. En obras previas en que el niño divino sirve como narrador-pienso ahora principalmente en "La oveja negra"-el protagonista central sufrió un rechazo absoluto de la sociedad y se mostró incapaz de adaptarse a ella. En La torre el éxito del héroe/narrador inspira la envidia de sus hermanos, y su fuerza física le hace capaz de aplastarlos si quiere. Ahora, al preferir ser matado a matar, el héroe muestra una verdadera toma de conciencia, y no simplemente una debilidad.Pero esto, escoger ser matado, hace más grave la cosa: declara, ya conscientemente, que no puede haber asimilación entre "la torre" y "la tierra", entre las fuerzas del bien y las del mal. Queda en pie la serie de oposiciones vigentes en obras anteriores.

Antes de llegar a esta decisión, el héroe sigue preparándose para la ceremonia en que se hará caballero. La noche de su vigilia-parte íntegra de la transición de niño a caballero-lo visten de rojo, negro, y blanco. Pero durante la vigilia, solo en la capilla, se desnuda de lo rojo y de lo negro:

me despojé rápidamente del manto rojo-y de toda la sangre que no iba a verter - y de la cota negra - y de la muerte que no me estaba destinada-. Me descalcé, y liberé mi cuerpo de toda prenda, excepto de la corta túnica de lino; una pureza que ignoraba, aunque no rechazaba...16

Vestido ya de blanco, el héroe se vuelve a la vez puro y sin defensa. Y en tal estado, a la mañana siguiente, sus hermanos lo agarran y lo matan.

En el simbolismo que tan cuidadosamente desarrollaron los alquimistas para representar el proceso de transformación que produce oro a partir de la baja materia-la unión, en otros términos, del cielo y tierra de que tanto hablaba Ferbe--el color rojo representa el estado más alto en una escala de colores que comienza por el negro y pasa por el blanco. El rojo, que representa no sólo sangre sino amor, representa la unión y la transformación de la materia y del espíritu, de lo negro y de lo blanco. Pero el héroe/narrador de $L a$ torre ve sólo rápidamente y de paso una visión de amor. Dice:

y a pesar del terror que me invadía, una verdad abrióse camino en tan febril y lúgubre esplendor: pues, como vuelo blanco entre las brumas de la noche, como el guerrero que asola y destruye más allá del odio, aleteaba esa palabra-todavía más ciega--que llaman los hombres amor. ${ }^{17}$

16 La torre vigía, p. 231.

${ }^{17}$ La torre vigia, p. 187 
Sólo con el amor puede perdonar Abel a Caín, puede perdonar Caín a Abel. Pero en La torre la figura de Caín se ha hecho demasiado terrorífica. De hecho, se ha multiplicado y crecido sobre las figuras de la envidia que aparecieron en obras anteriores. En La torre el miedo y el escape-todavía, más que nunca-dominan la conciencia del niño, y el "Gran Combate" queda en las sombras como una amenaza aterradora.

El amor sí aparece-de vez en cuando, como en las rápidas visiones del narrador de La torre-a través de las páginas de la obra de Matute. Pero, como el niño divino, florece brevemente, y no sobrevive a la luz violenta del sol de día. Porque el jardín en que brota - los naranjales de Primera memoria, y "La oveja negra", siempre trae dentro, como el mismo Jardín de Edén, el emblema de lo siniestro. Matia y Manuel se toman las manos en su jardín y se dicen sus secretos más hondos, mientras afuera espera Borja, con sus planes que llegarán a destruir a Manuel. La niña/narradora de "La oveja negra" también se encuentra momentáneamente en un jardín a causa del amor apasionado por su hijito. Pero ella no puede pagar al jardinero, y se les expulsa. El niño, más tarde reprocha a su madre: "Madre, debías tener algún dinero," 18 y desaparece luego de su vida, dejando a la narradora completamente inconsolable.

El mensaje parece ser obvio: el ser verdadero pide no un rechazo del "mundo" de la conciencia a favor de la inconsciencia, sino un acomodo entre los dos. Escoger o el negro o el blanco significa que uno sigue agarrado por uno u otro de los términos en oposición: un niño inocente, o un adulto despiadado, que, a fin de cuentas, resultan ser la misma cosa, como muchas obras de Matute muestran. Superar el conflicto requiere que medie entre los términos en oposición el amor-lo rojo-mediación que ningún héroe/víctima de Matute ha logrado hacer brotar.

El niño, en las obras de Matute que tenemos, siempre reaparecerá-como siempre volverá a desaparecer si esa unión momentánea que lo produjo se mantiene inestable. No es por accidente, por lo tanto, por lo que todos los niños del mundo conflictivo matuteano tienen una historia propia de separación: separación del niño de aquellos que quiere; separación entre los que quiere. Los niños de Matute, como el héroe de La torre, son arrancados del paraíso prematuramente, brutalmente. Rechazan el mundo de los adultos a causa de su traición, prefiriendo a cambio una pureza destinada a la muerte. Pero llevan implícita en su auto-inmolación, la promesa del Jardín, y el recuerdo de él, que, sin ellos, los adultos seguramente olvidarían. Recuerdan la posibilidad de superación en un mundo amenazado de muerte por el ritual fratricidio reactualizado generación tras generación por los hijos de Adán y Eva, nacid os fuera del Jardín, y sólo vagamente conscientes del origen divino que éste representa.

${ }_{18}$ Tres y un sueño, p. 118. 
Matute en su obra ha logrado representar en su forma más directa y violenta la lucha a muerte que es la vida ordinaria. Como tal, le han categorizado de pesimista, y de existencialista. Sin embargo, y esto es lo que he tratado de mostrar aquí, se nota debajo de este choque de fuerzas en oposición una intuición de unión y de superación que calificaría a esta autora no sólo de "existencialista" sino de visionaria. En su última obra manifiesta el esfuerzo de traspasar lo bueno y lo malo, y, aunque el protagonista no logra sostener tal visión, la vemos allí afirmada. Ahora hace falta constatar sólo que el haberlo realmente, totalmente, logrado habría significado no un fin distinto, sino silencio. Como dice Joyce Carol Oates en el prefacio a su libro de crítica New Heaven, New Earth:

Once one has crossed that threshold of which Kafka speaks, once one has directly experienced the divinity and unity of the universe, "evil" (or division) is eradicated, and "all is good." There is only affirmation. There is not even affirmation, but only existence. And one must "hold one's tongue."19

Después de una obra como La torre vigia, hay que escuchar con nueva atención el silencio que la ha seguido.

${ }^{19}$ New Heaven, New Earth (New York: The Vanguard Press, Inc., 1974), p. 4. 
